\title{
A gene for pachyonychia congenita is closely linked to the keratin gene cluster on $17 \mathrm{q} 12-\mathrm{q} 21$
}

Colin S Munro, Simon Carter, Steven Bryce, Mandy Hall, Jonathan L Rees, Lia Kunkeler, Anthea Stephenson, Tom Strachan

\begin{abstract}
Pachyonychia congenita (PC) is a group of hereditary syndromes which have in common a hypertrophic dystrophy of the distal nail, and are associated with a variety of additional features, notably various dyskeratoses of skin and mucous membranes. The pathology is unknown but the array of clinical features suggests the possibility of a keratin abnormality. In the present report we describe linkage analyses in a large $P C$ pedigree of the JacksonLawler type, a subtype which is characterised by multiple epidermal cysts, hair abnormalities, and natal teeth. The disease locus in this family was found to be tightly linked to markers mapping within, or very close to, the keratin type I cluster at 17q12-q21; maximum lod scores for linkage of the disease to a KRT10 polymorphism and to D17S800, a marker known to be very tightly linked to KRT10, were respectively $+4 \cdot 51$ and $+7 \cdot 73$, both at $\theta=0 \cdot 00$. Although always likely, our findings provide strong evidence of a keratin gene anomaly underlying an inherited disorder affecting epidermis, nail, hair, and mucosa. These findings permit testing to see if pachyonychia congenita shows any locus heterogeneity and suggest specific candidate keratin genes for mutation searching studies. In addition, they suggest a role for keratins in the phenomenon of natal dentition.
\end{abstract}

(f Med Genet 1994;31:675-678)

C S Munro

L Kunkeler

Department of Human Genetics, University of Newcastle upon Tyne, Ridley Building,

Claremont Place,

Newcastle upon Tyne

NE1 7RU, UK

$S$ Carter

$S$ Bryce

$M$ Hall

A Stephenson

T Strachan

Department of

Dermatology,

University of

Newcastle upon Tyne,

Royal Victoria

Infirmary,

Newcastle upon Tyne

NE1 4LP, UK

$\mathrm{J}$ L Rees

Correspondence to Professor Strachan.

Received 26 April 1994 Revised version accepted for publication 19 May 1994 simple epidermal cysts, perhaps arising from vellus hair follicles, but in some reports are true steatocysts with sebaceous glands attached. ${ }^{3}$
Jackson-Lawler type PC patients often have recurrent flexural infections resembling hidradenitis suppurativa. ${ }^{3-5}$ In this type also, natal teeth $^{46}$ and peculiarly straight, bushy eyebrow hair are regular features. A third clear group have pachyonychia, macular pigmentation, and amyloid deposition. ${ }^{78}$ Other types of PC which have been suggested ${ }^{1}$ are based on additional clinical features: corneal lesions and cataract, angular cheilosis, chronic candidiasis, ${ }^{9}$ hoarseness or other laryngeal lesions, alopecia, and mental retardation. There may be variants with onset later in life. ${ }^{10}$ In a total of about 200 cases, all these variants are relatively few and the variations minor, so they may not represent distinct subtypes. The pathogenesis of the pachyonychias is unknown, but most if not all of the clinical features are referable to disordered keratinisation. In support of this, ultrastructural histology in Jadassohn-Lewandowsky PC shows marked increases of tonofilaments in the peripheral cytoplasm of keratinocytes from the basal layer upwards. ${ }^{112}$ The blistering which occurs in some cases clinically resembles that in epidermolysis bullosa simplex (EBS), being worse in warm weather, and improving with age. EBS is now known to be the result of mutations in genes for the keratins of the basal layer of the epidermis. ${ }^{13-15}$ Mutations in genes for suprabasal keratins cause epidermolytic hyperkeratosis $^{16-18}$ and epidermolytic palmoplantar keratoderma. ${ }^{1920}$ Recently, familial keratosis palmaris et plantaris has also been shown to be tightly linked to the keratin type I gene cluster on $17 \mathrm{q}^{21}$

Keratin genes are clearly also candidate disease genes for each of the pachyonychia congenita syndromes. They are expressed in set pairs, each type I, acidic, keratin being coexpressed with one type II, basic, keratin. ${ }^{22}$ The pair expressed varies with tissue and circumstances but their genes are almost all clustered on two sites on chromosomes $12 \mathrm{q}$ (mostly type II genes) and $17 \mathrm{q}$ (type I genes). ${ }^{22}$ The existence in Glasgow of a very large pedigree of the Jackson-Lawler type provided us with an opportunity to test the hypothesis that PC is the result of keratin defects by investigating linkage of the disease to the keratin gene clusters.

\section{Materials and methods}

PATIENTS

Twenty-five affected members of a single family were identified from case records in three Glasgow hospitals, and by tracing of relatives. Cases were ascertained by two clinicians (LK, CM) on the basis of clinical examination (23 cases) 


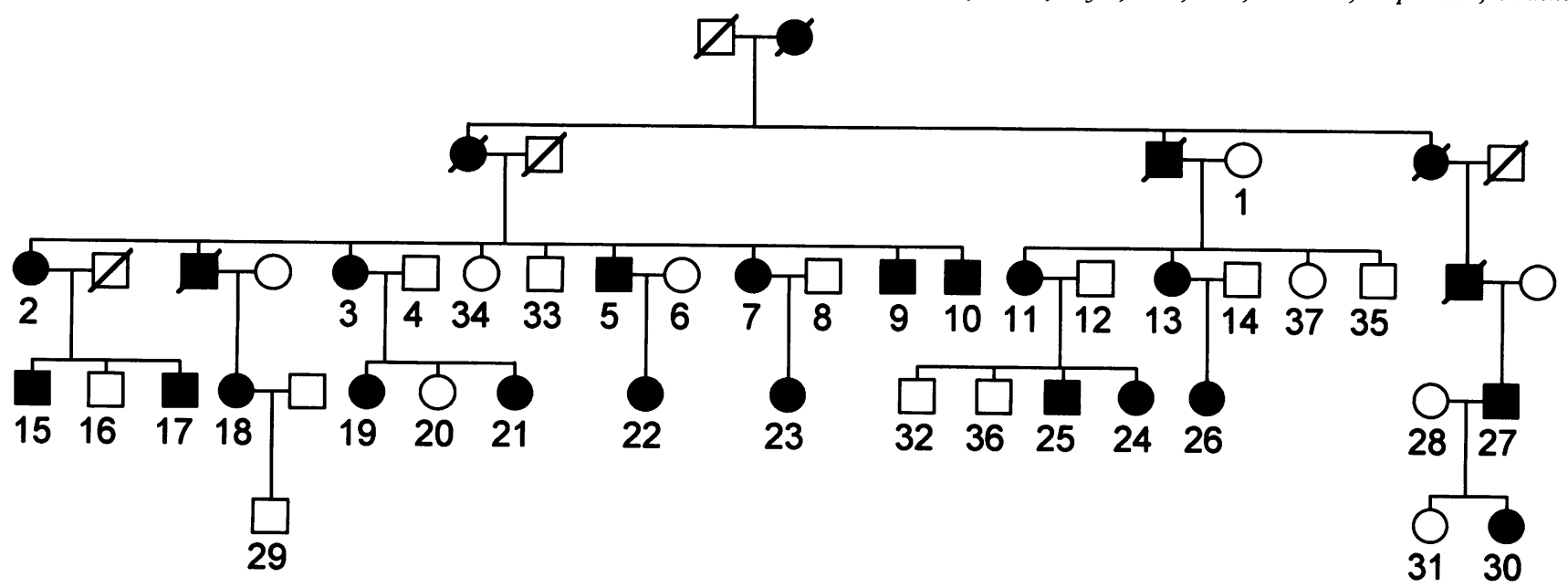

Figure 1 Pachyonychia congenita pedigree used for linkage analysis. Numbers of persons in pedigree identify the origin of DNA samples analysed in the corresponding lane numbers in figs 2 and 3.

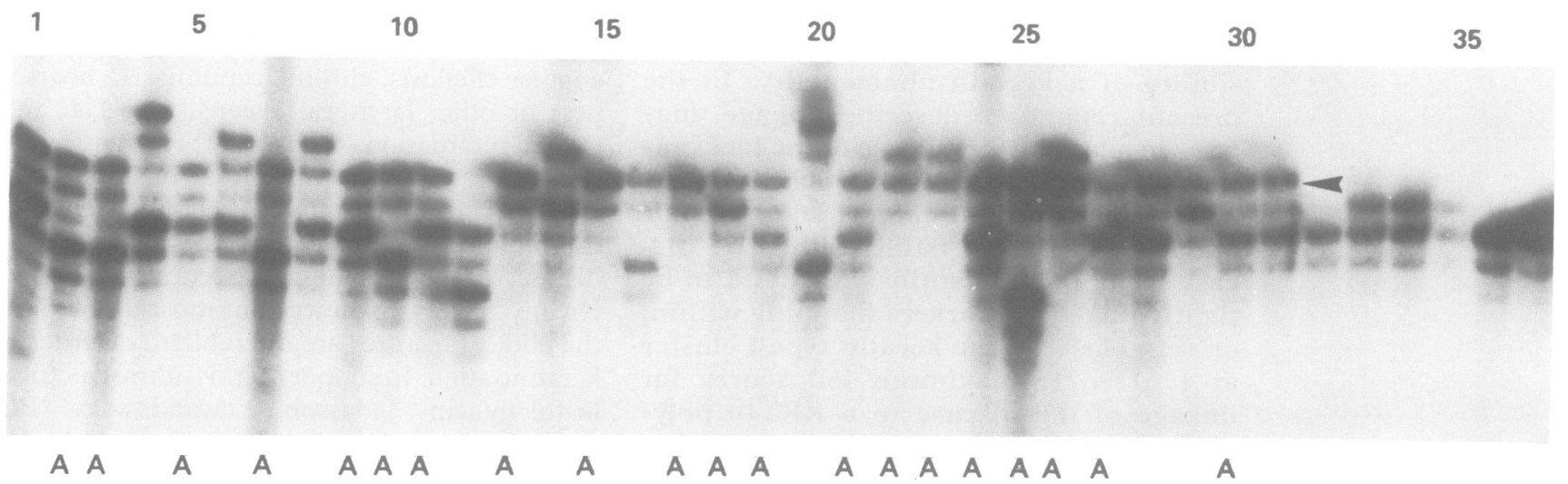

Figure 2 Typing results for microsatellite marker D17S800. Arrow marks the position of the allele segregating with disease. A=affected persons. Lanes 1-37 represent results from typing individual members of the pedigree as numbered in fig 1.

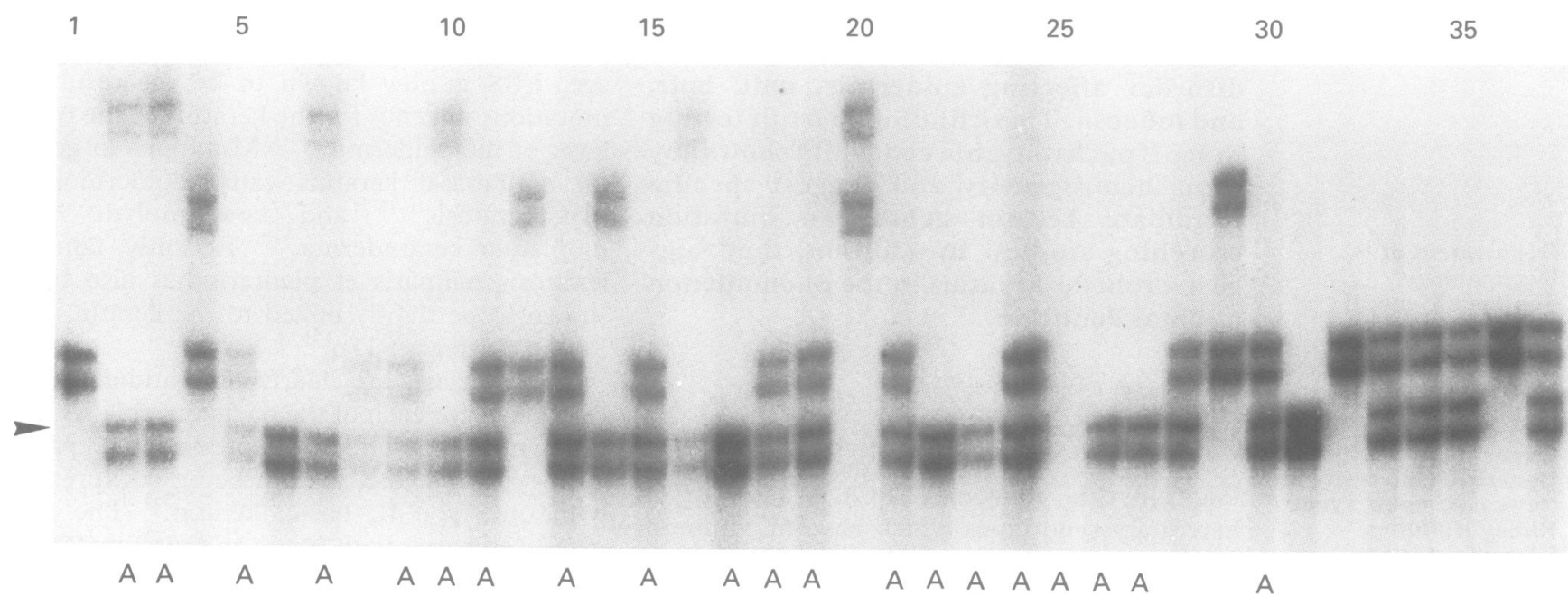

Figure 3 Typing results for a length polymorphism in the KRT10 gene. The individual alleles for this polymorphism each show two strong closely migrating bands, and four different alleles are apparent in this family. Of these, the smallest allele (identified by an arrow) is the one which segregates with the disease in this family. Lanes 1-37 represent results from typing individual members of the pedigree as numbered in fig $1 ;$ the apparent absence of alleles in lane 25 was a result of amplification failure.

Pairwise lod scores for pachyonychia congenita and $17 q$ markers

\begin{tabular}{llllllll}
\hline & \multicolumn{7}{l}{$L$ Lod score for recombination fraction } \\
\cline { 2 - 8 } Marker locus & 0.00 & 0.01 & 0.05 & 0.10 & 0.20 & 0.30 & 0.40 \\
\hline D17S800 & 7.73 & 7.60 & 7.09 & 6.43 & 5.01 & 3.44 & 1.69 \\
KRT10 & 4.51 & 4.44 & 4.13 & 3.74 & 2.91 & 2.02 & 1.05 \\
\hline
\end{tabular}

or telephone interview ( 2 cases). Blood samples were obtained from 20 affected persons and 17 other members, including 10 unaffected members with an affected parent, as shown in fig 1. Penetrance was complete, although the severity of disease varied (Kunkeler and Munro, in preparation).

\section{DNA TYPING}

Microsatellite marker D17S800 and a marker detecting keratin 10 length polymorphism have 
previously been described and typed using standard methods as described. ${ }^{21} 23$

\section{LINKAGE ANALYSIS}

Linkage analysis was performed using the data management package LINKSYS ${ }^{24}$ in conjunction with the computer program LINKAGE version $5 \cdot 1 .^{25}$

\section{Results}

As described in the Introduction, various findings have suggested that pachyonychia congenita may result from a keratin abnormality. As a first step in testing this hypothesis DNA samples from available members of a large pachyonychia congenita pedigree of the Jackson-Lawler type (fig 1) were typed for polymorphisms known to map in the immediate vicinity of keratin genes. A microsatellite marker D17S800, which is known to be very closely linked to the acidic KRT10 gene, ${ }^{21}$ showed an allele which had consistent segregation with the disease (fig 2 ). The resulting lod scores were significantly high, with a maximum of +7.73 at $\theta=0.00$ (see table). To verify this result we followed up by typing family members with a marker which identifies extensive length polymorphism within the coding sequence of the KRT10 gene. ${ }^{23}$ Again, as shown in fig 3, one allele was consistently found to segregate with the disease, and provided significantly positive lod scores, with a maximum of +4.51 at $\theta=0.00$ (table).

\section{Discussion}

The D17S800 marker is known to be very tightly linked to a length polymorphism described by Korge et $a l^{23}$ in the C terminal V2 subdomain of the KRT10 gene product; one recent report showed no recombination between these two markers in at least 25 informative meioses and cited a personal communication which also testified to the absence of recombination between these markers. ${ }^{21}$ Our results confirm the close linkage of these two markers, neither of which show recombination with the disease allele in the large PC pedigree which we have investigated. The KRT10 gene is known to map within a closely clustered group of acidic type I keratin genes, including KRT9, KRT13, KRT15, KRT 16 and KRT 19, and possibly also KRT 17, KRT20, and others. Our results, therefore, are consistent with the idea that this disorder is the result of a keratin abnormality. In view of the considerable phenotypic overlap between PC syndromes, it is quite possible that they are all the result of related or allelic keratin gene defects.

Disorders ascribed to defects in keratin genes include EB simplex (KRT5/KRT14), ${ }^{1314}$ including the Dowling Meara type, ${ }^{15}$ epidermolytic hyperkeratosis (KRT1/KRT10), ${ }^{16-18}$ and epidermolytic palmoplantar keratoderma (KRT9).${ }^{1920}$ In addition, familial keratosis palmaris et planataris is closely linked to the type I keratin cluster, suggesting the possible in- volvement of a keratin gene. ${ }^{21}$ Our present linkage results suggest that the hyperkeratosis and EBS-like blistering of PC will also be explained by defective keratin production, structure, organisation, or degradation, but it remains to be established which keratin(s) are involved in pathogenesis. The keratin(s) or regulatory elements involved in the various PCs will be ones which can be active in all the sites involved, namely palmoplantar skin, ventral nail, hair follicles, the corneal epithelium, and possibly sweat glands. Laryngeal mucosa, and, in Jadassohn-Lewandowsky PC, oral mucosa are also involved. Additionally, in JacksonLawler PC the premature eruption of teeth suggests an effect of the keratins expressed in fetal gingival and enamel epithelia. ${ }^{26}$

Adequate data on the keratins expressed by lesional tissue are not available, and no single keratin candidate which fulfils all these criteria is immediately apparent, but because abnormalities are present from the basal layer upwards in Jadassohn-Lewandowsky PC, abnormal keratins 5 or 14 are particular candidates for this variant. The ultrastructural appearances of Jackson-Lawler PC have not been reported. Of the keratin pairs, only those of simple epithelia ( $\mathrm{K} 8$ and $\mathrm{K} 18$ ) can be excluded for this variant since, exceptionally, both genes are in the chromosome $12 \mathrm{q}$ cluster. $^{22}$ The other type I keratin genes are all possible candidates; genes on chromosome $17 \mathrm{q}$ include KRT14, KRT10 (suprabasal expression), KRT16 ("hyperproliferation"), KRT15, and KRT19, and quite possibly KRT17 and KRT20. Many of these genes are also expressed in hair follicles and nail. ${ }^{27} 28$ The nail dystrophy does not begin until a few months of age, which suggests that expression of the defective gene is not constitutive but is a response to mild trauma; this could favour an abnormal induction of K16 expression. Genes encoding the hard keratins of hair and nail, and K12 (wet epithelia) and K13 (cornea) are less likely candidates because of their limited distribution. ${ }^{22}$ However, the disease state could also result from ectopic keratin gene expression secondary to defects in adjacent regulatory elements. Further work is required to identify the likeliest candidates for defects causing all forms of PC. One useful approach will be definition of the keratin types found in lesional tissues, especially when filaments accumulate in the epidermis $^{1112}$ or as amyloid. ${ }^{8}$

The demonstration that a keratin defect almost certainly underlies this rare condition has wider implications for understanding epidermal physiology, and also the pathogenesis of commoner skin diseases. The distal subungual hyperkeratosis, probably similar in mechanism to the hyperkeratosis of palmoplantar skin, resembles that seen in some forms of psoriasis, including Reiter's syndrome, and in dermatophyte infection of the nail. Patients with Jackson-Lawler PC have recurrent abscesses resembling the condition hidradenitis suppurativa, ${ }^{6}$ a disabling entity associated with follicular plugging in flexures. ${ }^{29}$ Familial hidradenitis, and steatocystoma multiplex without nail changes both exist. ${ }^{3031}$ Investigation of 
the defects of keratin in PC is thus relevant to the pathogenesis of these disorders.

Unusual hair is seen in Jackson-Lawler PC; eyebrows are notably bushy and grow perpendicularly out of the skin. This growth may be because of abnormal formation by the hair follicle, but the possibility also exists that the structural hair keratins are themselves abnormal. This hypothesis is supported by reports of abnormally dry, kinked scalp hair, ${ }^{4}$ and by our own observation (Kunkeler and Munro, in preparation) that limb hairs are also abnormally rigid.

Although always likely, our findings provide strong evidence for a keratin gene anomaly underlying an inherited disorder affecting epidermis, nail, hair, and mucosa. In addition, the suggested role for keratins in the phenomenon of natal dentition is intriguing, and may provide useful insights into the regulation of tooth eruption.

TS, CSM, and JLR are recipients of a project grant from the Wellcome Trust.

1 Feinstein A, Friedman J, Schewach-Millet M. Pachyonychia congenita. F Am Acad Dermatol 1988;19:705-11.

2 Jackson AD, Lawler SD. Pachyonychia congenita: a repor on six cases in one family. Ann Eugen 1951;16:142-6.

3 Clementi M, Cardin de Stefani E, Dei Rossi C, Avvent V, Tenconi R. Pachyonychia congenita Jackson-Lawler type: a distinct malformation syndrome. $B r f$ Dermatol 1986 ; 114:367-70

4 Soderquist NA, Reed WB. Pachyonychia congenita with epidermal cysts and other congenital abnormalities. Arch Dermatol 1968;97:31-3.

5 Todd P, Garioch J, Rademaker M, Susskind W, Gemel C, Thomson J. Pachyonychia congenita complicated by C, Thomson J. Pachyonychia congenita complicated by hidradenitis supp

6 Murray FA. Congenital anomalies of nails associated with teeth erupted at birth. $B r \mathcal{F}$ Dermatol 1921;33:409.

7 Buckley R, Cassuto J. Pachyonychia congenita. Arch Dermatol 1962;85:397-402.

8 Tidman MJ, Wells RS, MacDonald DM. Pachyonychia congenita with cutaneous amyloidosis and hyperpigmentation - a distinct variant. $\mathcal{f}$ Am Acad Dermato 1987;16:935-40.

9 Mawhinney H, Creswell S, Beare JM. Pachyonychia congenita with candidiasis. Clin Exp Dermatol 1981;6:145-9.

10 Paller AS, Moore JA, Scher R. Pachyonychia congenita tarda: a late-onset form of pachyonychia congenita. Arch Dermatol 1991;127:701-3.

11 Thormann J, Kobayasi T. Pachyonychia congenita Jadassohn-Lewandowsky. Acta Derm Venereol (Stockh) 1977 57:63-7.
12 Thomas DR, Jorizzo JL, Brysk MM, Tschen JA, Miller J, Tschen EH. Pachyonychia congenita: electron microscopic and epidermal glycoprotein assessment before
and during isotretinoin treatment. Arch Dermatol 1984; 120:1475-9.

13 Coulombe PA, Hutton ME, Letain A, Herbert A, Paller AS, Fuchs E. Point mutations in keratin 14 genes of epidermolysis bullosa simplex patients: genetic and function analyses. Cell 1991;66:1301-11.

14 Bonifas JM, Rothman AL, Epstein EH. Epidermolysis bullosa simplex: evidence in two families for keratin gene losa simplex: evidence in two families
abnormalities. Science 1991;254:1202-5.

15 Lane EB, Rugg EL, Navsaria H, et al. A mutation in the conserved helix terminating peptide of keratin 5 in hereditary skin blistering. Nature 1992;356:244-6.

16 Cheng J, Syder AJ, Yu QC, Letai A, Paller AS, Fuchs E. The genetic basis of epidermolytic hyperkeratosis: disorder of differentiation-specific epidermal keratin genes. Cell 1992;70:811-19.

17 Chipev CC, Korge BP, Markova N, et al. A leucine-proline mutation in the $\mathrm{H} 1$ subdomain of keratin- 1 causes epidermolytic hyperkeratosis. Cell 1992;70:821-8.

18 Rothnagel JA, Dominey AM, Dempsey LD, et al. Mutations in the rod domains of keratins 1 and 10 in epidermolytic hyperkeratosis. Science 1992;257:1128-30.

19 Torchard D, Blanchet-Bardon C, Serova O, et al. Epidermolytic palmoplantar keratoderma cosegregates with a keratin gene mutation in a pedigree with breast and ovarian keratin gene mutation in a pedigree with

20 Reis A, Hennies HC, Langbein L, et al. Keratin 9 gene mutations in epidermolytic palmoplantar keratoderma mutations in epidermolytic palmop
(EPPK). Nature Genet 1994;6:174-9.

21 Rogaev EI, Rogaeva EA, Ginter EK, et al. Identification of the genetic locus for keratosis palmaris et plantaris on chromosome 17 near the RARA and keratin type I genes. Nature Genet 1993;5:158-62.

22 Stack DP, Korge BP, James WD. Keratin and keratinization. f Am Acad Dermatol 1994;30:85-102.

23 Korge BP, Gan SQ, McBride OW, Mischke D, Steinert P. Extensive size polymorphism of the human keratin 10 chain resides in the $\mathrm{C}$ terminal V2 subdomain due to variable numbers and sizes of glycine loops. Proc Nat Acad Sci USA 1992;89:910-14.

24 Attwood J, Bryant S. A computer programme to make analysis with LIPED and LINKAGE easier to perform and less prone to input errors. Ann Hum Genet 1988;5: 259.

25 Lathrop GM, Lalouel JM. Easy calculation of lod scores and genetic risks on small computers. Am $\mathcal{f}$ Hum Gene 1984;36:460-5.

26 Gao Z, Mackenzie IC. Patterns of phenotypic expression of human junctional, gingival and reduced enamel epitheli in vivo and in vitro. Epithelial Cell Biol 1992;1:156-67.

27 Kitahara T, Ogawa $\mathrm{H}$. The extraction and characterization of human nail keratin. $\mathcal{F}$ Dermatol Sci 1991;2:402-6.

28 Stark HJ, Breitkreutz D, Limat A, et al. Keratins 1 and 10 or homologues as regular constituents of inner root sheath and cuticle cells in the human hair follicle. Eur 7 Cell Bio 1990;52:359-72.

29 Shelley WB, Cahn MM. The pathogenesis of hidradenitis suppurativa in man. Arch Dermatol 1955;72:562.

30 Fitzsimmons JS, Fitzsimmons EM, Gilbert G. Familia hidradenitis suppurativa: evidence in favour of single gene hidradenitis suppurativa: evidence in favour

31 transmission. F Med Genet $1984 ; 21: 281-5$. multiplex complicated by hidradenitis suppurativa. Arch Dermatol 1975;112:1132-4. 